\title{
Vaccine-Induced Human Antibody Responses to the Haemophilus influenzae b Polysaccharide in Severe Combined Immunodeficient Mice Engrafted with Human Leukocytes
}

\author{
ALEXANDER H. LUCAS, TODD E. SIFF, KAREN H. TRUJILLO, AND MARINA Y. KITAMURA
}

Children's Hospital Oakland Research Institute, Oakland, California 94609

\begin{abstract}
We examined the ability of severe combined immunodeficient (SEID) mice-human peripheral blood leukocyte (PBL) chimeras to respond to immunization with Haemophilus influenzae b polysaccharide (Hib PS) vaccines. Two to 3 wk after PBL engraftment, human-PBLSCID mice, prepared with PBL from one of five adult donors, were immunized with free or protein-conjugated Hib PS. Antibody to Hib PS was quantitated in preimmunization and postimmunization sera. Before immunization, anti-Hib PS antibody was detectable $(>10 \mathrm{ng} / \mathrm{mL})$ in three of $\mathbf{4 0}$ mice. Of the 37 human-PBL-SCID mice not having detectable serum antibody before immunization, 31 produced $\geq 20 \mathrm{ng} / \mathrm{mL}$ ( $\geq 2$-fold increase) anti-Hib PS antibody 2 to 3 wk after immunization. Both free and proteinconjugated forms of Hib PS were immunogenic. Geometric mean anti-Hib PS antibody levels ranged from 50 to 139 $\mathrm{ng} / \mathrm{mL}$. Vaccine-induced anti-Hib PS antibodies frequently expressed HibId-1, a cross-reactive idiotype that predominates the in vivo human antibody response to Hib PS. However, among mice engrafted with $\mathrm{PBL}$ from a single donor, the HibId-1 distribution was highly skewed, suggesting that clonally distinct $B$ cells were being stimulated in individual mice. These findings indicate that human PBL transplanted into SCID mice are functionally responsive to Hib PS antigenic challenge. This system may serve as a useful model for studying the regulation and cellular requirements for human polysaccharide immunity. (Pediatr Res 32: 132-135, 1992)
\end{abstract}

\section{Abbreviations}

SCID, severe combined immunodeficient

Hib, Haemophilus influenzae type b

PS, polysaccharide

PBL, peripheral blood leukocyte

Hu-PBL, human peripheral blood leukocyte

Hib-PS-D, Hib PS coupled to diphtheria toxoid

Hib PS-OMPC, Hib PS coupled to outer membrane complex of Neisseria meningitidis

Antibodies to PS antigens play a central role in protection from diseases caused by encapsulated bacteria. In contrast to protein antigens, immune responsiveness to PS generally develops late in ontogeny and is thought to be relatively independent

Received for rapid publication March 6, 1992; accepted March 12, 1992.

Correspondence: Alexander H. Lucas, Children's Hospital Oakland Research Institute, 747 52nd Street, Oakland, CA 94609.

Supported by U.S.P.H.S. Grant Al25008 and a grant from the Children's Hospital Oakland Research Institute Endowment Fund. of T cells. Our understanding of the induction and regulation of human PS immunity has been limited by the inability to reliably generate PS-specific antibody responses in vitro. The demonstration that mutant SCID mice (1) could be engrafted with functional hu-PBL (2) suggested to us that this system may be potentially useful for studying human PS immunity. We therefore determined whether hu-PBL-SCID mice were capable of responding to a well-defined and clinically relevant bacterial PS.

Hib is an encapsulated bacterium that is responsible for the majority of meningitis in North America and is the causative agent in other serious invasive diseases (3). The Hib capsular PS is an important virulence determinant (4), and antibodies to Hib PS confer protection from invasive Hib disease (5). Although children less than $2 \mathrm{y}$ of age are generally unresponsive to immunization with plain Hib PS, they do produce antibody when immunized with protein-conjugated forms of Hib PS (6). The mechanism(s) responsible for this phenomenon is not known, but presumably the coupling of protein carriers to the PS brings carrier-specific $T$ cells into play that promote the activation and differentiation of Hib PS-specific B cells. Pauciclonality is a striking feature of the antibody response to Hib PS, as evidenced by limited clonotypic diversity $(7,8)$, common use of an unmutated subgroup II $\mathrm{V}_{\kappa}$ region derived from the A2 gene (9), and predominance of VHIII chains (10-12). A crossreactive idiotype, designated HibId-1, is a marker for anti-Hib PS antibodies having the $\mathrm{V}_{\kappa}$ IIA 2 region (13). Antibodies bearing HibId-1 are present in $85 \%$ or more of immunized adult subjects and compose more than half of the vaccine-induced serum antiHib PS antibody (13).

The ability to generate human antibody responses to Hib PS in hu-PBL-SCID mice could provide a system for addressing the issues of $\mathrm{T}$ cell regulation and repertoire expression, which heretofore have not been amenable to experimental manipulation. In this study, we show that hu-PBL-SCID mice produce human antibodies to Hib PS after immunization with various Hib PS vaccines. The induced antibodies frequently express HibId-1, which is characteristic of the in vivo response.

\section{MATERIALS AND METHODS}

Mice. C.B-17 scid/scid severe combined immunodeficient mutant mice (SCID) were bred and maintained at the Children's Hospital Oakland Research Institute Animal Facility. Homozygous breeding pairs were obtained from Dr. Paul Kincade, Oklahoma Medical Research Foundation, Oklahoma City, OK, with the permission of Dr. Melvin Bosma, Fox Chase Cancer Research Institute, Philadelphia, PA. Mice were housed in sterilized microbarrier units with sterilized bedding. They were provided autoclaved food and water.

Isolation of PBL and preparation of hu-PBL-SCID chimeras. PBL were isolated from heparinized normal adult peripheral 
blood by centrifugation through Ficoll-Hypaque. Each SCID mouse received an intraperitoneal injection of 40 to $50 \times 10^{6}$ PBL in $0.5 \mathrm{~mL}$ RPMI medium.

Vaccines and immunizations. Two to $3 \mathrm{wk}$ after PBL injection, hu-PBL-SCID mice were immunized intraperitoneally with 0.2 mL PBS containing either $4 \mu \mathrm{g}$ purified Hib PS (provided by Dr. Porter Anderson, University of Rochester, Rochester, NY), 2.5 $\mu \mathrm{g}$ Hib PS conjugated to $1.8 \mu \mathrm{g}$ diphtheria toxoid (Hib PS-D, ProHibit Vaccine; Connaught Labs., Swiftwater, PA), or $2 \mu \mathrm{g}$ Hib PS conjugated to $12 \mu \mathrm{g}$ of Neisseria meningitidis outer membrane protein complex (Hib PS-OMPC, Merck Sharp \& Dohme Research Labs., West Point, PA). Blood was taken before and at variable times after immunization, and serum was stored frozen until tested.

Immunoassays. Total serum human $\mathrm{Ig}$ was measured in ELISA. Microtiter wells were coated with goat anti-human Ig (mouse Ig absorbed; Tago Inc., Burlingame, CA). Dilutions of hu-PBL-SCID sera were incubated in wells and, after washing, the bound human Ig was detected using alkaline phosphataseconjugated goat anti-human Ig (Caltag Inc., S. San Francisco, $\mathrm{CA}$ ) followed by addition of p-nitrophenylphosphate. Ig levels in sera were calculated by comparison to a standard curve generated with purified human IgG.

Antibodies to Hib PS were measured in a sensitive radioantigen binding assay similar to previously published methods (14), except that precipitates rather than supernatants were counted. Quantities of anti-Hib PS in sera were calculated by comparison to a standard curve generated with a reference human antiserum provided by the U.S. Office of Biologics and assigned a value of $70 \mu \mathrm{g}$ anti-Hib PS/mL. In this assay, the lower limit of detection is $10 \mathrm{ng} / \mathrm{mL}$ Hib PS-specific antibody. Linear increases in bound cpm of ${ }^{125} \mathrm{I}-\mathrm{Hib}$ PS are obtained with levels of anti-Hib PS ranging from 10 to $150 \mathrm{ng} / \mathrm{mL}$.

A previously described ELISA was used to analyze the species origin of anti-Hib PS antibodies in hu-PBL-SCID sera (15). Dilutions of hu-PBL-SCID sera were incubated in microtiter wells coated with tyraminated Hib PS, followed by the addition of alkaline phosphatase-conjugated murine MAb specific for either human IgG, IgM, kappa or lambda (The Binding Site, San Diego, CA), or goat antibodies specific for murine Ig. Substrate was then added and OD at $405 \mathrm{~nm}$ was determined.

HibId-1 expression by anti-Hib PS antibodies was quantitated as previously described $(13,16)$ by measuring the degree to which a goat anti-HibId-1 antiserum inhibited the ${ }^{125} \mathrm{I}-\mathrm{Hib}$ PS binding activity of test sera.

\section{RESULTS AND DISCUSSION}

Human Ig production in hu-PBL-SCID mice. In keeping with the observations of Mosier et al. (2), hu-PBL-SCID mice produced human serum Ig. Ig appeared in the serum 1 wk after PBL injection. Peak levels were attained at 2 to $4 \mathrm{wk}$ after PBL engraftment and remained relatively constant for $\sim 8 \mathrm{wk}$. Table 1 summarizes the human Ig levels in hu-PBL-SCID mice produced with PBL from five donors. The Ig levels showed marked variation among mice engrafted with the same PBL innoculum.

Vaccine-induced anti-Hib PS antibody responses in hu-PBL$S C I D$ mice. Two to $3 \mathrm{wk}$ after PBL injection, and before immunization, hu-PBL-SCID sera were tested for the presence of anti-Hib PS antibody using a sensitive radioantigen binding assay that detects as little as $10 \mathrm{ng} / \mathrm{mL}$ of anti-Hib PS antibody. Three of 40 mice had detectable antibody before immunization. HuPBL-SCID mice were immunized with either plain Hib PS, Hib PS-D, or Hib PS-OMPC. The individual antibody responses of these mice after immunization are shown in Figure 1 and the results are summarized in Table 1 . Antibody levels varied considerably among individual mice that were reconstituted with PBL from the same donor and that were immunized with the same vaccine. Of the $37 \mathrm{hu}-\mathrm{PBL}-\mathrm{SCID}$ mice that did not have detectable antibody before immunization, 31 responded to vac- cination with $\geq 2$-fold rise in serum anti-Hib PS antibody level. The geometric mean antibody levels ranged from 50 to $139 \mathrm{ng} /$ $\mathrm{mL}$, and no striking differences were apparent in the magnitude of the antibody responses induced by the different Hib PS vaccines. Immunization of hu-PBL-SCID mice (reconstituted with PBL from donor D) with either plain Hib PS or Hib PS-D, did not lead to significantly different frequencies of responders or different levels of serum anti-Hib PS antibody $(p>0.7)$.

As noted above, three of 40 hu-PBL-SCID mice had detectable anti-Hib PS antibody before immunization. These mice were reconstituted with PBL from either donor A or donor E (Table 1). To compare spontaneous antibody production with vaccineinduced synthesis, 12 SCID mice were reconstituted with PBL from donor $\mathrm{E}$ but were not immunized. The anti-Hib PS antibody levels were then monitored weekly for $8 \mathrm{wk}$. As shown in Figure 1, two mice produced measurable antibody. Maximal levels $(70$ and $22 \mathrm{ng} / \mathrm{mL})$ were attained $2 \mathrm{wk}$ after PBL injection and declined thereafter. The other 10 mice did not produce detectable antibody during the 8 wk of analysis. These data indicate that if spontaneous production of anti-Hib PS antibody occurs, it will be apparent within the first 2 wk after PBL injection. Thus, for hu-PBL-SCID mice engrafted with donor $\mathrm{E}$ PBL, the frequency of spontaneous anti-Hib PS antibody synthesis in the absence of immunization was two in 12 . This contrasts to a responder ( $\geq 20 \mathrm{ng} / \mathrm{mL}$ anti-Hib PS) frequency of seven of 10 , which was obtained when hu-PBL-SCID prepared with donor E PBL were immunized with Hib PS-OMPC (Fig. 1 and Table 1). Therefore, hu-PBL-SCID mice that have no detectable anti-Hib PS antibody at the time of vaccination (2 to 3 wk after PBL injection), but do synthesize antibody after vaccination, are most likely responding by an antigen-driven mechanism.

The observation that anti-Hib PS antibody is produced in some unimmunized hu-PBL-SCID mice is not surprising because virtually all adults have "natural" serum anti-Hib PS antibody (14). Presumably, Hib PS-specific antibody secreting cells are present in peripheral blood, and on occasion they continue to secrete antibody or are induced to secrete antibody upon transfer into SCID mice. The expression of "preformed" autoantibody secreting cells in SCID mice has been demonstrated with PBL from patients with primary biliary cirrhosis (17), systemic lupus erythematosus (18), and rheumatoid arthritis (19).

Our findings suggest that two populations of Hib PS-specific $\mathrm{B}$ cells are being functionally expressed in hu-PBL-SCID mice: those occurring in low frequency that spontaneously secrete antibody upon adoptive transfer and those occurring in higher frequency that remain quiescent upon transfer unless activated by specific antigenic stimulus.

HibId-1 expression in $h u-P B L-S C I D$. Postvaccination sera containing sufficient levels of antibody for testing were examined for expression of HibId-1, a cross-reactive idiotype restricted to human anti-Hib PS antibodies having $V_{K}$ IIA2 L chains (13). Hibld- 1 is expressed in $85 \%$ or more of immunized adults and composes on the average more than half of the serum anti-Hib PS antibody. In keeping with these in vivo findings, Hibld-1 was prevalent among hu-PBL-SCID anti-Hib PS antibodies (Table 2). However, HibId-1 levels showed marked individual variation among immunized hu-PBL-SCID mice reconstituted with a single donor PBL population; some mice produced antibody that was entirely Hibld-1-positive, whereas others had entirely HibId1-negative antibody. This skewed distribution suggests that distinct Hib PS-specific B cell clones are being functionally stimulated in some individual hu-PBL-SCID mice.

The vaccine-induced HibId- 1 -positive anti-Hib PS antibody in hu-PBL-SCID mice was of human origin because murine antiHib PS antibodies do not express HibId-1 (16, and Lucas A, unpublished results). Several sera containing sufficient levels of HibId-1-negative antibody for analysis were found by ELISA to have human but not murine anti-Hib PS antibody (data not shown). In addition, immunization of SCID mice with either 
Table 1. Serum antibody responses of hu-PBL-SCID mice immunized with Hib PS vaccines

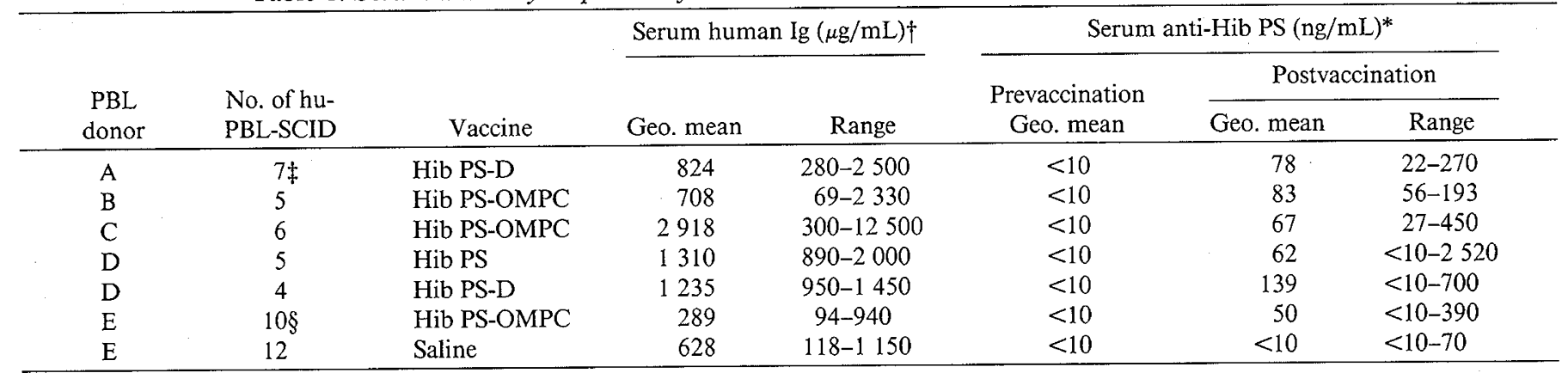

* Hu-PBL-SCID mice were immunized 2 to $3 \mathrm{wk}$ after PBL injection. Serum was obtained immediately before and 2 to $3 \mathrm{wk}$ after immunization, and anti-Hib PS antibody was quantified using radioantigen binding assay. For calculation of geometric means (Geo. mean) in postvaccination samples, sera having $<10 \mathrm{ng} / \mathrm{mL}$ were assigned a value of $5 \mathrm{ng} / \mathrm{mL}$.

$\dagger$ Measured in sera obtained 2 to $3 \mathrm{wk}$ after PBL injection.

$\ddagger$ Originally eight mice in this group, but one mouse that had detectable anti-Hib PS before immunization was excluded.

$\S$ Originally 12 mice in this group, but two mice that had detectable anti-Hib PS before immunization were excluded.

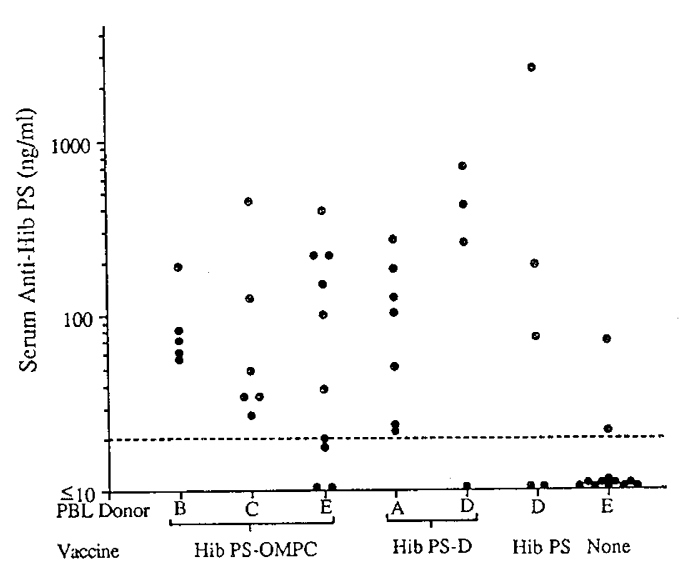

Fig. 1. hu-PBL-SCID antibody responses after vaccination. Each circle represents the serum anti-Hib PS antibody level in an individual huPBL-SCID mouse. SCID mice were vaccinated 2 to 3 wk after PBL injection, and sera obtained 2 to $3 \mathrm{wk}$ after vaccination were analyzed for anti-Hib PS using a radioantigen binding assay. Three mice that had detectable antibody before immunization were excluded: one from donor $\mathrm{B}$ group and two from donor E group (Hib PS-OMPC).

Table 2. HibId-1 expression in hu-PBL-SCID postvaccination sera

\begin{tabular}{cll}
\hline $\begin{array}{c}\text { PBL } \\
\text { donor }\end{array}$ & \multicolumn{1}{c}{ Vaccine } & $\begin{array}{c}\text { \% of total anti-Hib PS } \\
\text { expressing HibId-1 in } \\
\text { individual sera* }\end{array}$ \\
\hline A & Hib PS-D & $100 ; 100 ; 81 ; 0 ; 0$ \\
B & Hib PS-OMPC & $100 ; 7$ \\
C & Hib PS-OMPC & $2 ; 18$ \\
D & Hib PS & $100 ; 46 ; 0$ \\
D & Hib PS-D & $100 ; 14 ; 7$ \\
E & Hib PS-OMPC & $100 ; 100 ; 100 ; 21 ; 18$ \\
\hline
\end{tabular}

* Serum was obtained 2 to 3 wk after immunization, and HibId-1 level was quantified by measuring the degree to which anti-Hibld-1 inhibited ${ }^{125} \mathrm{I}$-Hib PS binding activity in individual sera. Sera were chosen based on availability and the presence of $\geq 50 \mathrm{ng}$ anti-Hib PS antibody per mL.

plain Hib PS $(n=10)$ or Hib PS-D $(n=10)$ did not generate detectable $(<10 \mathrm{ng} / \mathrm{mL}$ ) serum anti-Hib PS antibody (Lucas A, unpublished observation). Therefore, both HibId-1-positive and -negative anti-Hib PS antibodies produced in hu-PBL-SCID mice are human derived.

Similar to our findings of skewed HibId-1 expression, evidence was found by Saxon et al. (20) for limited B cell expression in
hu-PBL-SCID. Serum human Ig was pauciclonal based upon isoelectric heterogeneity and kappa/lambda distribution, and variable region heavy chain-family use was skewed and restricted among mice reconstituted with the same PBL population. Based upon their findings, the concern was raised by these authors that the hu-PBL-SCID system may not serve as an adequate model for normal human immune function. This caveat is substantive, and further applications of the hu-PBL-SCID model must take into account this issue of restricted $B$ cell expression as well as the currently unknown mechanism(s) by which high levels of human Ig are spontaneously produced in these chimeras. Nonetheless, our findings indicate that despite the low but measurable frequency of spontaneous anti-Hib PS antibody synthesis a population of human Hib PS-specific B cells responds in hu-PBLSCID mice to antigenic challenge with production of antibodies idiotypically characteristic of the in vivo response. Therefore, the hu-PBL-SCID model may be useful in future studies aimed at delineating the role of $\mathrm{T}$ cells and cytokines in influencing PS immunity.

Acknowledgments. The authors thank Paul Kincade for his provision of SCID breeding pairs, Ray Langley for his efforts in the early phases of this work, and Don Reason for his helpful suggestions.

\section{REFERENCES}

1. Bosma GC, Custer RP, Bosma MJ 1983 A severe combined immunodeficiency mutation in the mouse. Nature 301:527-530

2. Mosier DE, Gulizia RJ, Baird SM, Wilson DB 1988 Transfer of a functional human immune system to mice with severe combined immunodeficiency. Nature 335:256-259

3. Schlech WF, Ward JI, Band JD, Hightower A, Fraser DW, Broome C 1985 Bacterial meningitis in the United States, 1978-1981: the national meningitis surveillance study. JAMA 253:1749-1754

4. Moxon ER, Deich RA, Connelly C 1984 Cloning of chromosomal DNA from Haemophilus influenzae. Its use for studying the expression of type b capsule and virulence. J Clin Invest 73:298-306

5. Alexander HE, Heidelberger M, Leidy G 1944 The protective or curative element of type b $H$. influenzae rabbit serum. Yale J Biol Med 16:425-440

6. Weinberg GA, Granoff DM 1988 Polysaccharide-protein conjugate vaccines for the prevention of Haemophilus influenzae type $\mathrm{b}$ disease. J Pediatr 113:621-631

7. Insel RA, Kittelberger A, Anderson P 1985 Isoelectric focusing of human antibody to the Haemophilus influenzae b capsular polysaccharide: restricted and identical spectrotypes in adults. J Immunol 135:2810-2816

8. Tarrand J, Scott MS, Takes PE, Nahm MH 1989 Clonal characterization of the human antibody repertoire to Haemophilus influenzae type b polysaccharide I. Demonstration of three types of $\mathrm{V}$ regions and their association with $\mathrm{H}$ and $\mathrm{L}$ chain isotypes. J Immunol 142:2519-2526

9. Scott MG Crimmins DL, McCourt DW, Zocher I, Thiebe R, Zachau HG, Nahm MH 1989 Clonal characterization of the human antibody repertoire to Haemophilus influenzae b polysaccharide III. A single $V_{k} I I$ gene and one of several $\mathrm{J}_{K}$ genes are joined by an invariant arginine to form the most common L chain V region. J Immunol 143:4110-4116 
10. Scott MG, Tarrand JJ, Crimmins DL, McCourt DW, Siegel NR, Smith CE, Nahm MH 1989 Clonal characterization of the human IgG antibody repertoire to Haemophilus influenzae b polysaccharide II. IgG antibodies contain $\mathrm{VH}$ genes from a single family and VL genes from four VI families. J Immunol 143:293-298

11. Silverman GJ, Lucas AH 1991 Variable region diversity in human circulating antibodies specific for the capsular polysaccharide of Haemophilus influenzae type b. Preferential usage of two types of VH3 heavy chains. J Clin Invest 88:911-920

12. Adderson EA, Shackelford PG, Quinn A, Carroll WL 1991 Restricted Ig H chain usage in the human antibody response to Haemophilus influenzae type b capsular polysaccharide. J Immunol 147:1667-1674

13. Lucas AH, Langley RJ, Granoff DM, Nahm MH, Kitamura MY, Scott MG 1991 An idiotypic marker associated with a germ-line encoded kappa light chain variable region that predominates the vaccine-induced human antibody response to the Haemophilus influenzae b polysaccharide. J Clin Invest 88:1811-1818

14. Robbins JB, Parke JC, Schneerson R, Whisnant JK 1973 Quantitative measurement of "natural" and immunization-induced Haemophilus influenzae type b capsular polysaccharide antibodies. Pediatr Res 7:103-110
15. Anthony BF, Concepcion NF, McGeary SA, Ward JI, Heiner DC, Shapshak P, Insel RA 1982 Immunospecificity and quantitation of an enzyme-linked immunosorbent assay for group B streptococcal antibody. J Clin Microbiol $16: 350-354$

16. Lucas AH, Granoff DM 1990 A major cross-reactive idiotype associated with human antibodies to the Haemophilus influenzae b polysaccharide: expression in relation to age and IgG subclass. J Clin Invest 85:1158-1166

17. Krams SM, Dorschkind K, Gershwin ME 1989 Generation of biliary lesions after transfer of human lymphocytes into severe combined immunodeficient (SCID) mice. J Exp Med 170:1919-1930

18. Duchosal MA, McConahey PJ, Robinson CA, Dixon FJ 1990 Transfer of systemic lupus erythematosous in SCID mice. J Exp Med 172:985-988

19. Tighe H, Silverman GJ, Kozin F, Tucker R, Gulizia R, Peebles C, Lotz M, Rhodes G, Machold K, Mosier DE, Carson DA 1990 Autoantibody production in severe combined immunodeficient mice reconstituted with synovial cells from rheumatoid arthritis patients. Eur J Immunol 20:1843-1848

20. Saxon A, Macy E, Denis K, Tary-Lehmann M, Witte O, Braun J 1991 Limited B cell repertoire in severe combined immunodeficient mice engrafted with peripheral blood mononuclear cells derived from immunodeficient and normal humans. J Clin Invest 87:658-665 